\title{
Accessory spleen arising from the gastric fundus mimicking gastrointestinal stromal tumor following splenectomy: A case report
}

\author{
GUANGYAO WANG ${ }^{1}$, PING CHEN $^{1}$ and LIANG ZONG ${ }^{2}$ \\ ${ }^{1}$ Gastrointestinal Surgery Department, Su Bei People's Hospital of Jiangsu Province, Yangzhou University, \\ Yangzhou, Jiangsu 225001, P.R. China; ${ }^{2}$ Department of Gastrointestinal Surgery, \\ Graduate School of Medicine, University of Tokyo, Tokyo, Japan
}

Received June 12, 2013; Accepted November 1, 2013

DOI: 10.3892/etm.2013.1415

\begin{abstract}
The current case report presents an accessory spleen mimicking gastrointestinal stromal tumor (GIST) of the stomach in a patient who had undergone a splenectomy 20 years previously. A 61-year-old male, who presented with upper abdominal discomfort lasting three months, underwent gastrointestinal endoscopy. Gastroscopy and endoscopic ultrasonography revealed a smooth, hemispherical mass of $\sim 2 \mathrm{~cm}$ in diameter, with homogenous echogenicity originating from the gastric muscular layer. Abdominal contrast-enhanced computed tomography showed that the well-marginated ovoid mass was $\sim 2.6 \times 1.9 \mathrm{~cm}$ in size. The patient was diagnosed with GIST. Subsequent therapy consisted of partial gastrectomy. The pathological results indicated the mass contained splenic tissue, which confirmed it to be an accessory spleen. Changes in the postoperative platelet count were noted. The observations of this case study highlight that platelet count should be used as a routine indicator for monitoring accessory spleen arising from gastric fundus lesion.
\end{abstract}

\section{Introduction}

The occurrence of an accessory spleen is relatively common and observed in $10-30 \%$ of autopsy patients $(1,2)$. Accessory spleens are congenital foci of healthy splenic tissues that are separate from the main body of the spleen (3). They often originate from a failed fusion of the splenic anlage located in the dorsal mesogastrium during the 5th week of fetal development (4). Although they have been found at sites from the

Correspondence to: Professor Ping Chen, Gastrointestinal Surgery Department, Su Bei People's Hospital of Jiangsu Province, Yangzhou University, 98 Nantong West Road, Yangzhou, Jiangsu 225001, P.R. China

E-mail: chen86ky@126.com

Key words: accessory spleen, gastrointestinal stromal tumor, splenectomy diaphragm to the scrotum, the vast majority are located in the spleen region, usually in the splenic hilum or along the splenic vessels or associated ligaments. The majority of accessory spleens appear as small nodules arising from adjacent organs, such as the kidney, adrenal gland and pancreas (5-10). Cases arising from the stomach are relatively rare. In the present case, the accessory spleen was unusual, presenting as a gastrointestinal stromal tumor (GIST) of the stomach at endoscopy.

This study was approved by the ethics committee of Su Bei People's Hospital of Jiangsu Province (Yangzhou, China). The patient consented to the publication of this study.

\section{Case report}

A 61-year-old male was admitted to the Department of Gastroenterology of Su Bei People's Hospital of Jiangsu Province (Yangzhou, China) presenting with an upper abdominal discomfort of 3 months in duration. Past and family histories were non-contributory and the patient did not smoke or consume alcohol and had undergone a splenectomy 20 years earlier. Upon admission, physical examination and laboratory data, including peripheral blood counts, were all unremarkable. The platelet count was $1.48 \times 10^{11} / 1$. The tumor markers showed no abnormalities and were as follows: Carbohydrate antigen (CA)50, $3.75 \mathrm{KU} / 1$ (normal range, <35.00); CA19-9, $2.09 \mathrm{KU} / 1$ (normal range, <35.00); $\alpha$-fetoprotein, $4.58 \mathrm{ng} / \mathrm{ml}$ $(<20.00)$; and carcinoembryonic antigen, $0.95 \mathrm{ng} / \mathrm{ml}$ (normal range, <5.00). Gastrointestinal endoscopy identified a fusiform mass at the posterior wall of the upper gastric fundus (Fig. 1). Endoscopic ultrasonography (EUS) revealed a tumor with low homogenous echogenicity originating in the gastric muscular layer (Fig. 2). Abdominal contrast-enhanced computed tomography (CT) showed a well-marginated ovoid mass $\sim 2.6 \times 1.9 \mathrm{~cm}$ in size located close to the gastric fundus (Fig. 3). A diagnosis of gastric GIST was made. Initially, endoscopic submucosal dissection was considered, however, the perforation involved rendered the problem difficult to repair by this method. Instead, gastroscopy was combined with laparoscopy. Under a laparoscope, the tumor was located at the posterior wall of the upper gastric fundus and was $\sim 2.5 \times 3.0 \mathrm{~cm}$ in size. Due to abdominal adhesions in the gastric fundus, separation and 


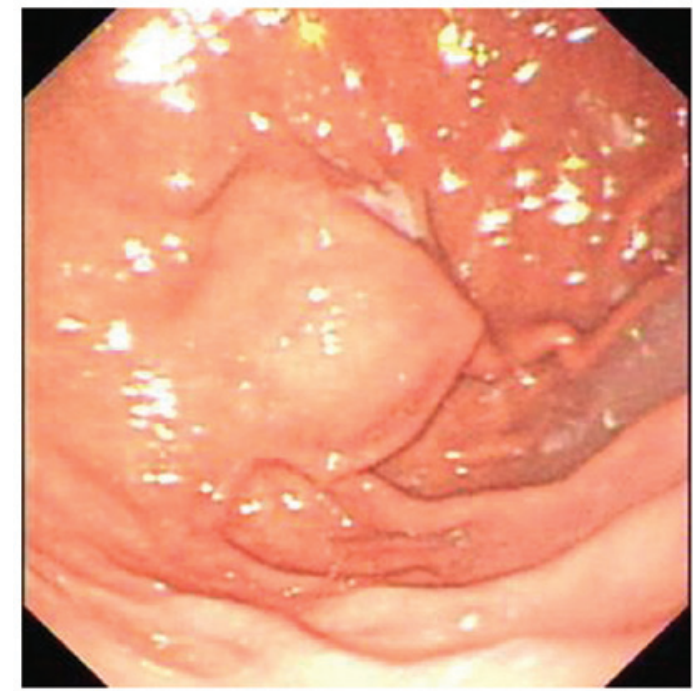

Figure 1. Gastrointestinal endoscopy revealed a fusiform mass at the posterior wall of the upper gastric fundus

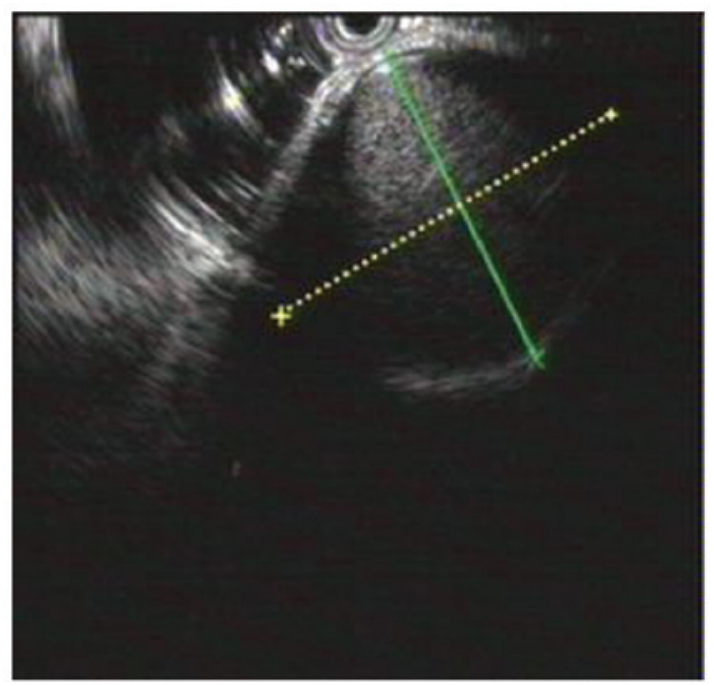

Figure 2. Endoscopic ultrasonography revealed a tumor with low homogenous echogenicity originating in the gastric muscular layer.

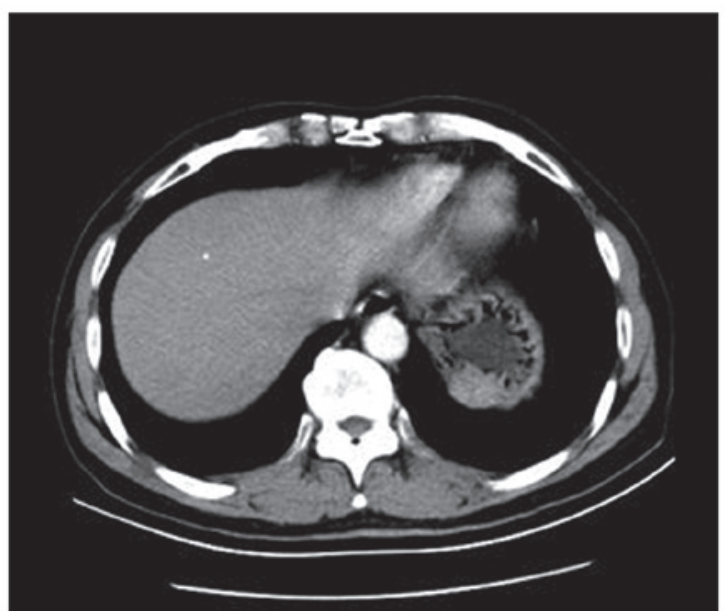

Figure 3. Abdominal contrast-enhanced computed tomography showed a well-marginated ovoid mass of $\sim 2.6 \mathrm{x} 1.9 \mathrm{~cm}$ in size located close to the gastric fundus.

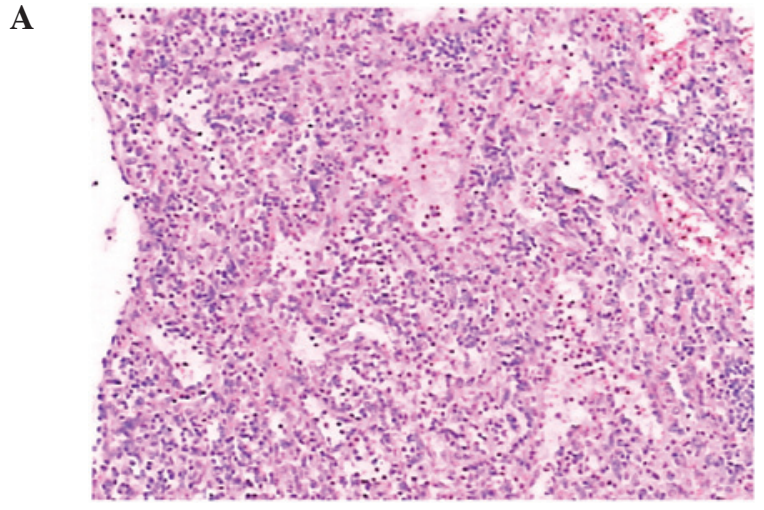

B

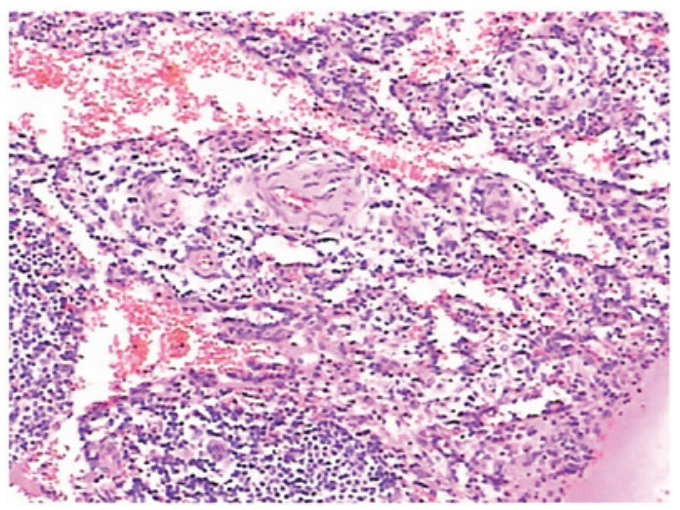

Figure 4. Histological examination of (A) and (B) revealed representative structures in red pulp and in the perifollicular zone of the human spleen. A number of sinusoidal spaces containing red blood cells were found to contain monocytes and lymphocytes.

exposure was difficult. Open surgery was performed with enterolysis and partial gastrectomy. Histological examination identified specific representative structures in the red pulp and perifollicular zone of the human spleen. The tissue was largely composed of monocytes and lymphocytes and numerous sinusoidal spaces containing red blood cells were interspersed among these cells. The terminal end of the capillary branches of the arteriole sheaths were also identified, and were intermixed with lymphocytes and plasmocytes (Fig. 4). These results indicated that the mass contained splenic tissue, which confirmed it to be an accessory spleen.

\section{Discussion}

The current case report presents the diagnosis and treatment of an accessory spleen adjoining the stomach fundus, which appeared as a GIST at endoscopy in a patient who had undergone a splenectomy 20 years earlier. It has been reported that accessory spleens can have compensatory hypertrophy of residual splenic tissue following splenectomy and occasionally reach $3-5 \mathrm{~cm}$ in size (2). The accessory spleen observed in the present case appeared to be a GIST, considering that the patient had a history of splenectomy.

The following diagnostic approach can be considered effective when the diagnosis is unclear. CT is an important imaging technique used to evaluate the abdomen. It can identify the shape of accessory spleens (oval or round) and whether attenuation is identical to that of a proper splenic parenchyma prior to and following administration of contrast medium (1). 
Familiarity with the CT features of accessory spleens is useful to determine a diagnosis (6). Typically, accessory spleens are round or oval and the attenuation is identical to that of the proper splenic parenchyma prior to and following administration of contrast medium (6). Vascular branches arising from the splenic artery can be observed on dynamic CT (1). Endoscopic ultrasonography is able to show whether a mass with the homogenous parenchymal texture has originated from extragastric tissue, such as splenic parenchyma. The patient in the present case study had previously undergone a splenectomy, therefore it was impossible to compare the accessory spleen to proper splenic parenchyma. EUS-guided fine needle aspiration is beneficial for diagnosis of accessory spleen, which mimics a gastric subepithelial mass observed in histological examination (11). However, certain accessory spleens mimic an enlarged lymph node or tumor arising from adjacent organs, such as the kidney, adrenal gland or pancreas (12-15). Similarly, accessory spleens may be differentiated from metastatic lesions or lymphadenopathy when they are enhanced to the same degree as the spleen (1). In such cases, technetium $99 \mathrm{~m}$ sulfur colloid scintigraphy provides an easy method of establishing the identity of ectopic splenic tissues $(5,6)$. The mass mimicking GIST was readily identified by radionuclide imaging in the present case, resulting in the definite diagnosis of accessory spleens. An accessory spleen should be suspected in this type of case. In addition, ectopic splenic tissue may be caused by autotransplantation of splenic cells within the peritoneal cavity resulting from traumatic disruption of the splenic capsule $(16,17)$.

Although an accessory spleen is usually found incidentally with no clinical significance in the majority of patients $(1,6)$, it may occasionally be relevant to detection and characterization in clinical situations (18-20). Accessory spleens may become symptomatic due to spontaneous rupture, hemorrhage, embolism or torsion. The clinical significance of a residual accessory spleen post-splenectomy varies according to the individual conditions. Surgeons must be aware of their presence when the intention is to remove functional splenic tissues. The return of splenic function caused by compensatory enlargement of ectopic splenic tissues has been implicated in the recurrence of hematological disorders, such as thrombocytopenic purpura (18-20).

During follow-up, the platelet count of the present patient increased to $3.92 \times 10^{11} / 1$ on the second day following surgery and a high level of $4.10 \times 10^{11} / 1$ was observed on day 9 . The patient peripheral blood count returned to normal after 2 weeks, and there was no evidence of recurrence. Platelet count usually increases within 2-3 days of splenectomy, peaks between 7 and 14 days and then gradually decreases and returns to normal after 1-2 months (21). This condition may cause venous thrombosis if the platelet count increases abnormally. Once thrombosis has extended to the superior mesenteric vein, it may cause extensive necrosis of its convolutions. Similarly, high postoperative platelet counts can easily lead to deep venous thrombosis of the lower limbs, resulting in pulmonary embolism and even mortality. For this reason, changes in platelet count should be observed carefully following a splenectomy. Appropriate treatment based on the platelet count and liver function may provide good therapeutic effects.
In conclusion, patients who present with accessory spleen arising from gastric fundus following splenectomy should undergo careful follow-up by imaging examination, including CT. If the clinical course is uneventful and the patient remains asymptomatic without any abnormalities in physical and laboratory examinations, then splenectomy should not be performed. Changes in postoperative platelet count should be taken into account. If splenectomy is necessary, platelet count should be used as a routine monitoring indicator.

\section{References}

1. Halpert B and Gyorkey F: Lesions observed in accessory spleens of 311 patients. Am J Clin Pathol 32: 165-168, 1959.

2. Beahrs JR and Stephens DH: Enlarged accessory spleens: CT appearance in postsplenectomy patients. AJR Am J Roentgenol 135: 483-486, 1980.

3. Freeman JL, Jafri SZ, Roberts JL, Mezwa DG and Shirkhoda A: CT of congenital and acquired abnormalities of the spleen. Radiographics 13: 597-610, 1993.

4. Dodds WJ, Taylor AJ, Erickson SJ, Stewart ET and Lawson TL: Radiologic imaging of splenic anomalies. AJR Am J Roentgenol 155: 805-810, 1990.

5. Mortelé KJ, Mortelé B and Silverman SG: CT features of the accessory spleen. AJR Am J Roentgenol 183: 1653-1657, 2004.

6. Gayer G, Zissin R, Apter S, et al: CT findings in congenital anomalies of the spleen. Br J Radiol 74: 767-772, 2001.

7. Hayward I, Mindelzun RE and Jeffrey RB: Intrapancreatic accessory spleen mimicking pancreatic mass on CT. J Comput Assist Tomogr 16: 984-985, 1992.

8. Harris GN, Kase DJ, Bradnock H and Mckinley MJ: Accessory spleen causing a mass in the tail of the pancreas: MR imaging findings. AJR Am J Roentgenol 163: 1120-1121, 1994.

9. Stiris MG: Accessory spleen versus left adrenal tumor: computed tomographic and abdominal angiographic evaluation. J Comput Assist Tomogr 4: 543-544, 1980.

10. Tsuchiya N, Sato K, Shimoda N, et al: An accessory spleen mimicking a nonfunctional adrenal tumor: a potential pitfall in the diagnosis of a left adrenal tumor. Urol Int 65: 226-228, 2000.

11. Ahn JY, Jung HY, Kim do H, et al: Diagnosis of an accessory spleen mimicking a gastric submucosal tumor using endoscopic ultrasonography-guided fine-needle aspiration. Korean J Gastroenterol 59: 433-436, 2012.

12. Seo T, Ito T, Watanabe $Y$ and Umeda T: Torsion of an accessory spleen presenting as an acute abdomen with an inflammatory mass. US, CT, and MRI findings. Pediatr Radiol 24: 532-534, 1994.

13. Valls C, Monés L, Gumà A and López-Calonge E: Torsion of a wandering accessory spleen: CT findings. Abdom Imaging 23: 194-195, 1998.

14. Coote JM, Eyers PS, Walker A and Wells IP: Intra-abdominal bleeding caused by spontaneous rupture of an accessory spleen: the CT findings. Clin Radiol 54: 689-691, 1999.

15. Pérez Fontán FJ, Soler R, Santos M and Facio I: Accessory spleen torsion: US, CT and MR findings. Eur Radiol 11: 509-512, 2001.

16. Brewster DC: Splenosis. Report of two cases and review of the literature. Am J Surg 126: 14-19, 1973.

17. Fleming CR, Dickson ER and Harrison EG Jr: Splenosis: autotransplantation of splenic tissue. Am J Med 61: 414-419, 1976.

18. Facon T, Caulier MT, Fenaux P, et al: Accessory spleen in recurrent chronic immune thrombocytopenic purpura. Am J Hematol 41: 184-189, 1992.

19. Antevil J, Thoman D, Taller J and Biondi M: Laparoscopic accessory splenectomy with intraoperative gamma probe localization for recurrent idiopathic thrombocytopenic purpura. Surg Laparosc Endosc Percutan Tech 12: 371-374, 2002.

20. Budzynski A, Bobrzyński A, Sacha T and Skotnicki A: Laparoscopic removal of retroperitoneal accessory spleen in patient with relapsing idiopathic thrombocytopenic purpura 30 years after classical splenectomy. Surg Endosc 16: 1636, 2002.

21. Koyanagi N, Iso Y, Higashi H, Kitano S and Sugimachi K: shunt patency. Am J Surg 156: 29-33, 1988. 